\title{
Disassortative mating in tristylous Eichhornia paniculata (Pontederiaceae)
}

\author{
S. C. H. Barrett, \\ A. H. D. Brownt and \\ J. S. Shore*
}
* Department of Botany, University of Toronto, Toronto, Ontario, Canada M5S 1A1 and $\dagger$ CSIRO, Division of Plant Industry, P.O. Box 1600, Canberra, ACT 2601, Australia

Populations of the tristylous, self-compatible diploid Eichhornia paniculata (Spreng.) Solms. (Pontederiaceae) display wide variation in floral traits likely to influence the mating system. Progeny tests of open-pollinated plants collected from two populations in N.E. Brazil with contrasting structures (trimorphic, dimorphic) were used to investigate mating patterns. The two loci that govern the inheritance of style length were used as marker genes. A model that measures the magnitude of disassortative mating was developed using the progeny test data. Since the model does not distinguish between selfing and assortative mating, outcrossing estimates are likely to be underestimated. Using the model it was shown that the mating patterns of the two populations were strikingly different. In the tristylous population a high level of disassortative mating was estimated $(t=0.903)$ with no significant differences among the floral morphs. In the dimorphic population $(L, M)$ the rate of disassortative mating of the long-styled morph was $t=0 \cdot 657$, whereas all matings in the mid-styled morph were either selfed or assortative. Selfing in the mid-styled morph is due to alteration of the position of short-level stamens resulting in automatic self-pollination. The consequence of this mating asymmetry on the dynamics of selection at loci controlling floral trimorphism is discussed.

\section{INTRODUCTION}

In the majority of heterostylous plant populations, outbreeding among the floral morphs is enforced by a sporophytically controlled self-incompatibility system (Lewis, 1949; Nettancourt, 1977). However, the strength of self-incompatibility can vary among heterostylous taxa and in several species high self-compatibility is reported (e.g., Ganders, 1975; Barrett, 1979). In self-compatible heterostylous species, opportunities exist for selfand intra-morph fertilisations and mating patterns are likely to vary with population structure and local conditions during flowering.

Populations of the tristylous, self-compatible, diploid Eichhornia paniculata (Spreng.) Solms. (Pontederiaceae) display wide variation in floral traits likely to influence the mating system. Populations can be trimorphic, dimorphic or monomorphic with self-pollinating, semi-homostylous variants common in non-tristylous populations (Barrett, 1985a, 1985b). This variation suggests that variable outcrossing rates are a feature of the mating system of the species. To investigate this possibility, rates of disassortative mating were determined in two natural populations of $E$. paniculata from N.E. Brazil with contrasting structures. In this paper we develop analytical procedures for the estimation of mating system parameters in tristylous species, using the loci governing style length as genetic markers, and present estimates of disassortative mating for the floral morphs within the two Brazilian populations.

\section{MATERIALS AND METHODS}

\section{Sites and sampling}

The populations chosen for study in N.E. Brazil were located at Recife, Pernambuco (B-5) and União dos Palmares, Alagoas (B-9). Population B-5 was trimorphic $(L, M, S)$ and composed of approximately 1000 plants growing at high density along a $50 \mathrm{~m}$ section of roadside ditch. Population B-9 was dimorphic $(L, M)$ and contained 108 flowering plants scattered at low density in a wet pasture. The frequencies of floral morphs in the two populations were B-5: $L 0 \cdot 35, M 0 \cdot 36, S 0 \cdot 29$; B-9: $L 0 \cdot 26, M 0 \cdot 74$. The majority of $M$ plants in population B-9 possessed flowers with modified short-level stamens with a single anther adjacent to mid-level stigmas as a result of filament 
elongation of this stamen. This condition occurs commonly in E. paniculata, results in automatic self-pollination, and is associated with the breakdown of tristyly to semi-homostyly in the species (see Barrett, 1985a).

In each population seed was collected separately from individual plants of the floral morphs during May, 1982. Records of the style morph of each maternal parent were made. A total of 150 families were sampled from B-5 and 26 families from B-9. A random sample of 67 families from B-5 and all families from B-9 were subsequently used in progeny tests. Seeds from these families were germinated and plants were grown to flowering in a heated glasshouse at Toronto. On flowering the style morph of each plant was recorded and data for individual families tabulated. Details of sample sizes for each population are presented in table 3; progeny size was at least 30 in nearly all families.

\section{Data analysis}

Estimates of outcrossing rates in the floral morphs were based on observation of the segregation of style lengths in individual families, in conjunction with information on the genetics of style length in E. paniculata. Segregation data from controlled crosses and selfs of E. paniculata are consistent with a genetic model involving two linked diallelic loci $(S, M)$ with $S$ epistatic to $M$ (S. C. H. Barrett, unpublished data); details of this work will be published elsewhere. Following this model, genotypes for the three floral morphs are: $L$ $\mathrm{sm} / \mathrm{sm}, M-\mathrm{sm} / \mathrm{sM}, \mathrm{sM} / \mathrm{s} M, S-\mathrm{sm} / \mathrm{Sm}, \mathrm{sM} / \mathrm{SM}$, $s m / S M, s M / S m$. Since E. paniculata is selfcompatible, three additional genotypes for the $S$ morph could occur $(S m / S m, S M / S M, S m / S M)$. These were not recovered from population B-5, but have been artificially produced by controlled selfing. Recombination data obtained so far indicate that the $S$ and $M$ loci are tightly linked.

\section{Estimation of disassortative mating}

Let $\left\{G_{i}: i=1, \ldots, 7\right\}$ denote respectively the vector of frequencies in the adult population of the genotypes $s m / s m, \quad s m / s M, \quad s M / s M, \quad s m / S m$, $s M / S M, s m / S M$ and $s M / S m$, where the last two genotypes are the coupling and repulsion double heterozygotes respectively. Consider first the selfed progeny of these genotypes. Let $\boldsymbol{A}$ be a $7 \times 3$ matrix, whose elements are the proportions of the long-, mid- and short-styled phenotypes in the selfed progeny of each maternal genotype. The three columns correspond to the three progeny phenotypes, and the seven rows refer to the seven maternal genotypes in the above order. The matrix $\boldsymbol{A}$ is given in full in table 1, where $r$ is the recombination fraction between the two loci.

Next consider the outcross progeny that result from legitimate pollinations, i.e., pollen deriving only from anthers at the same level as the respective stigmas. There are four pollen genotypes, namely $s m, s M, S m$ and $S M$. Their frequencies depend on the maternal phenotype. We assume that these frequencies can be estimated from those of the adult plants. These pollen frequencies are specified as $p(I, j)$, where $I$ is the maternal phenotype ( $L$, $M$ or $S$ ) and $j$ is the pollen genotype. Thus the frequencies on long-styles are:

$$
\begin{aligned}
p(L, s m)= & {\left[G_{2}+G_{4}+G_{6}(1-r)+G_{7} r\right] / 2\left(1-G_{1}\right) } \\
p(L, s M)== & {\left[G_{2}+2 G_{3}+G_{5}+G_{6} r\right.} \\
& \left.+G_{7}(1-r)\right] / 2\left(1-G_{1}\right) \\
p(L, S m)= & {\left[G_{4}+G_{6} r+G_{7}(1-r)\right] / 2\left(1-G_{1}\right) } \\
p(L, S M)= & {\left[G_{5}+G_{6}(1-r)+G_{7} r\right] / 2\left(1-G_{1}\right) . }
\end{aligned}
$$

The pollen frequencies on mid-styles are:

$$
\begin{aligned}
p(M, s m)= & {\left[2 G_{1}+G_{4}+G_{6}(1-r)\right.} \\
& \left.+G_{7} r\right] / 2\left(1-G_{2}-G_{3}\right) \\
p(M, s M)= & {\left[G_{5}+G_{6} r+G_{7}(1-r)\right] / 2\left(1-G_{2}-G_{3}\right) } \\
p(M, S m)= & {\left[G_{4}+G_{6} r+G_{7}(1-r)\right] / 2\left(1-G_{2}-G_{3}\right) } \\
p(M, S M)= & {\left[G_{5}+G_{6}(1-r)\right.} \\
& \left.+G_{7} r\right] / 2\left(1-G_{2}-G_{3}\right) .
\end{aligned}
$$

The pollen frequencies on short-styles are:

$$
\begin{aligned}
& p(S, s m)=\left[G_{1}+G_{2} / 2\right] /\left(G_{1}+G_{2}+G_{3}\right) \\
& p(S, s M)=\left[G_{3}+G_{2} / 2\right] /\left(G_{1}+G_{2}+G_{3}\right) \\
& p(S, S m)=p(S, S M)=0
\end{aligned}
$$

Using these pollen frequencies the expected phenotypic frequencies of progeny from outcrosses with legitimate pollen can be formulated. For example, long-styled $(\mathrm{sm} / \mathrm{sm})$ maternal plants yield:

$$
\begin{array}{lc}
\text { Long-styled: } \quad\left[G_{2}+G_{4}+G_{6}(1-r)\right. \\
& \left.+G_{7} r\right] / 2\left(1-G_{1}\right) \\
\text { Mid-styled: } \quad\left[\begin{array}{l}
G_{2}+2 G_{3}+G_{5}+G_{6} r \\
\\
\end{array} \quad G_{7}(1-r)\right] / 2\left(1-G_{1}\right)
\end{array}
$$

Short-styled: $\quad\left[G_{s}\right] / 2\left(1-G_{1}\right)$

where $G_{s}=G_{4}+G_{5}+G_{6}+G_{7}$. 
Table 1 Matrix of probabilities of phenotypic proportions of selfed progeny (A) and legitimately outcrossed progeny (B) for each maternal genotype. $\left(G_{s}=G_{4}+G_{5}+G_{6}+G_{7}\right)$. The seven rows of the matrices are for the seven maternal genotypes, and the three columns are the three progeny phenotypes: long-, mid-, and short-styled

$$
\begin{aligned}
& A=\left[\begin{array}{lll}
1 & 0 & 0 \\
0 \cdot 25 & 0 \cdot 75 & 0 \\
0 & 1 & 0 \\
0 \cdot 25 & 0 & 0 \cdot 75 \\
0 & 0 \cdot 25 & 0 \cdot 75 \\
(1-r)^{2} / 4 & r(2-r) / 4 & 0 \cdot 75 \\
r^{2} / 4 & (1-r)^{2} / 4 & 0 \cdot 75
\end{array}\right] \\
& B=\left[\begin{array}{ccc}
\frac{G_{2}+G_{4}+G_{6}(1-r)+G_{7} r}{2\left(1-G_{1}\right)} & \frac{G_{2}+2 G_{3}+G_{5}+G_{6} r+G_{7}(1-r)}{2\left(1-G_{1}\right)} & \frac{G_{s}}{2\left(1-G_{1}\right)} \\
\frac{2 G_{1}+G_{4}+G_{6}(1-r)+G_{7} r}{4\left(1-G_{2}-G_{3}\right)} & \frac{2 G_{1}+G_{4}+2 G_{5}+G_{6}(1+r)+G_{7}(2-r)}{4\left(1-G_{2}-G_{3}\right)} & \frac{G_{s}}{2\left(1-G_{2}-G 3\right)} \\
0 & \frac{G_{1}+G_{s} / 2}{1-G_{2}-G_{3}} & \frac{G_{s}}{2\left(1-G_{2}-G_{3}\right)} \\
\frac{2 G_{1}+G_{2}}{4\left(1-G_{s}\right)} & \frac{G_{2}+2 G_{3}}{4\left(1-G_{s}\right)} & 0 \cdot 5 \\
0 & \frac{r\left(2 G_{1}+G_{2}\right)+G_{2}+2 G_{3}}{4\left(1-G_{s}\right)} & 0 \cdot 5 \\
\frac{(1-r)\left(2 G_{1}+G_{2}\right)}{4\left(1-G_{s}\right)} & \frac{(1-r)\left(2 G_{1}+G_{2}\right)+G_{2}+2 G_{3}}{4\left(1-G_{s}\right)} & 0 \cdot 5 \\
\frac{r\left(2 G_{1}+G_{2}\right)}{4\left(1-G_{s}\right)} & & 0 \cdot 5
\end{array}\right]
\end{aligned}
$$

Let $\boldsymbol{B}$ be a $7 \times 3$ matrix, whose elements are the expected proportions of progeny phenotypes from legitimate matings for each maternal genotype (table 1). Remarkably, the frequency of shortstyled progeny on all four genotypes of maternal short-styled plants is $1 / 2$.

The remaining possible pollinations for outcross progeny are of two types. First, there may be outcrosses between two different plants of the same morph, that is, phenotypic assortative outcrossing. In the cases of long-styled and homozygous mid-styled maternal plants, the phenotypic expectations in the progeny are identical with those of selfing. The heterozygous mid-styled plants $(\mathrm{sm} / \mathrm{sM})$ are expected to yield:

$$
\begin{aligned}
\text { Long-styled: } & G_{2} / 4\left(G_{2}+G_{3}\right) \\
\text { Mid-styled: } & 1-G_{2} / 4\left(G_{2}+G_{3}\right) \\
\text { Short-styled: } & 0
\end{aligned}
$$

The frequency of short-styled outcrossed progeny, from assortative mating, for all four genotypes of short-styled maternal plants is 0.75 , which is identical with the expectation under selfing.
The second type of remaining possible pollinations are illegitimate, i.e., disassortative outcrossing in which pollen from a different morph arises from anthers at a different level than the style. Assuming that all relevant anthers contribute equally, then the expected proportions for progeny phenotypes are formally equivalent to legitimate outcrosses. Thus the frequency of this class of mating cannot be told apart from legitimate out. crossing by the progeny testing method.

\section{Estimation of maternal genotype frequencies}

The first step in the estimation procedure is to classify the maternal genotypes from the given set of progeny arrays by likelihood ratio test (Brown et al., 1975). This requires relatively large progeny sizes to discriminate between the two mid-styled genotypes and the four short-styled genotypes. To calculate the expectations, the values of the population parameters $G_{i}, r$ and outcrossing $(t)$ are required. For the purpose of likelihood ratio tests, we use the observed values of $G_{1}, G_{2}+G_{3}$ and $G_{s}$ from a large independent sample and assume $t=$ 1.0 and $r=0$, that is we assume all progeny are outcrossed. 


\section{RESULTS}

\section{Estimation of maternal genotype frequencies}

The observed proportions of long, mid- and shortstyled progeny in each open pollinated family for population B-5 are plotted in fig. 1. For mid-styled parents, the families clustered into two classes, depending on whether long-styled progeny were present or absent. The female parents were thus deduced to be either $s m / s M$ or $s M / s M$, respectively. The estimated ratio of $G_{2}: G_{3}$ in the populations was therefore $22 / 2$ in B-5 and $16 / 4$ in B-9. The progenies of short-styled plants in population B-5 also formed two clusters, differing in the presence or absence of long-styled progeny (fig. 1). This gave a tentative ratio of $\left(G_{4}+G_{6}\right) /\left(G_{5}+\right.$ $\left.G_{7}\right)=17 / 5$. Thus $G_{1}=0.35, G_{2}=0.36 \times 22 / 4=$ $0.33, G_{3}=0.03, G_{4}+G_{6}=0.224$ and $G_{5}+G_{7}=$ $0 \cdot 066$. These values for the parameters $G_{i}$, although incompletely specified, allow the expected proportion of the progeny phenotypes to be calculated again assuming $r=0$. The proportions are given in table 2, along with the observed segregation of style morphs in open-pollinated progenies from the two populations.

It is evident in fig. 1 that the progenies from different plants of the same maternal genotype are heterogeneous in their proportions of the phenotypes. Chi-square tests (Brown et al., 1975) showed that this heterogeneity was statistically significant in three cases (table 3 ). The heterogeneity between progenies could be due to either variation in outcrossing rate or variation in pollen allele frequencies among maternal plants. If variation in outcrossing rate were the sole cause, the points in fig. 1 would lie on a steep line of constant $M: S$ ratio, passing through the apex. In contrast, the observed points are scattered across the triangle. Apparently variation in pollen allele frequencies is the major source of heterogeneity. This can arise if the effective outcrossed pollen for one family orginates from one or a few male parents (Schoen and Clegg, 1984). Since a relatively large number of progenies, each of similar size, contributes towards the total counts in table 2 , it is unlikely that the restriction of pollen sources within families will affect our overall estimates of disassortative mating.

\section{Estimation of disassortative mating}

For each of the three classes of maternal plants, the method of maximum likelihood was used to obtain estimates of the rate of disassortative mating ( $t$ ) by solution of the three likelihood equations in the single parameter $t$. Specifically for population B-5 the likelihoods are:

Long-styled: $\quad(1-0.577 t)^{312}(0 \cdot 354 t)^{208}$

$$
(0 \cdot 223 t)^{132}
$$

Mid-styled: $\quad(0 \cdot 25+0 \cdot 109 t)^{244}$

$$
\begin{aligned}
& (0 \cdot 75-0 \cdot 336 t)^{294}(1-0 \cdot 227 t)^{34} \\
& (0 \cdot 227 t)^{149}
\end{aligned}
$$

Short-styled: $\quad(1+t)^{305}(3-t)^{360}$.

The standard errors of the maximum likelihood estimates (table 3) were also found (Mather, 1951). These values assume that the maternal genotype frequencies are known exactly, which is not the case. However, the estimates of these frequencies came from large, independent samples. For the short-styled parents, the simplified model of con-
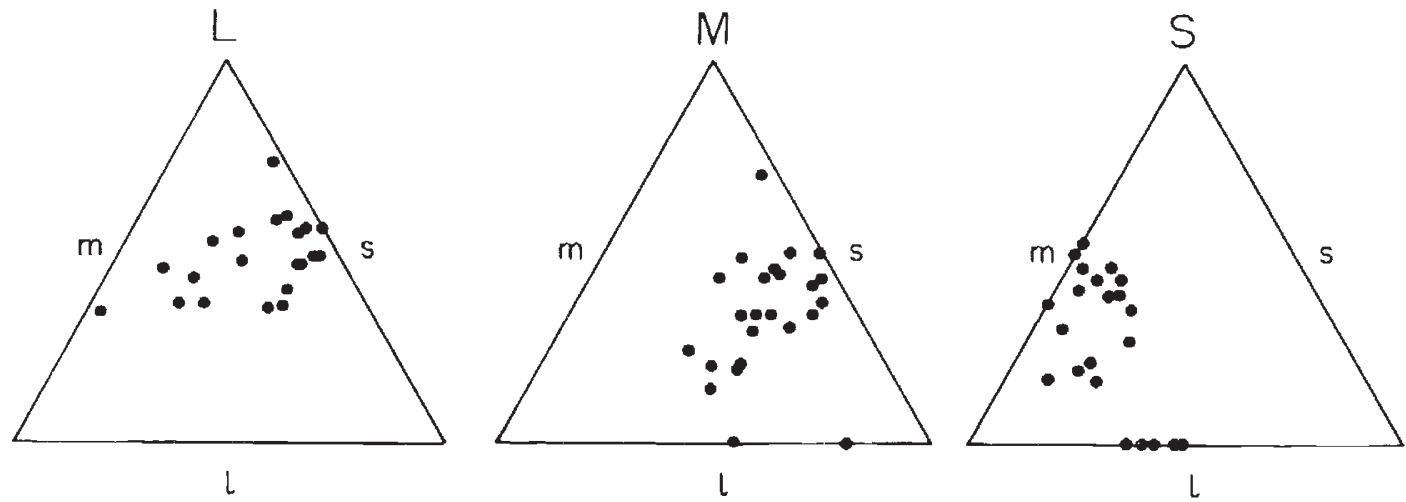

Figure 1 Distributions of floral morphs $(l, m, s)$ in open-pullinated families from $L, M$, or $S$ parents in population B-5. Fach point represents a single fanily and specifies the proportion of style morphs within the family as perpendicular distances from the point to the three sides of the equilateral triangle. For further details of plotting method, see Crosby (1949). 
Table 2 Observed numbers of floral morphs in open-pollinated progenies of Eichhornia paniculata, and expected proportions under complete selfing and disassortative mating

\begin{tabular}{|c|c|c|c|c|c|}
\hline \multirow{2}{*}{$\begin{array}{l}\text { Maternal } \\
\text { plants }\end{array}$} & \multirow[b]{2}{*}{ No. of families } & & \multicolumn{3}{|c|}{ Expected } \\
\hline & & & Observed & selfing & disassortative \\
\hline \multicolumn{6}{|l|}{ Pop. B-5 } \\
\hline \multirow[t]{3}{*}{ Long } & 21 & $L$ & 312 & 1 & 0.423 \\
\hline & & $M$ & 208 & 0 & 0.354 \\
\hline & & $S$ & 132 & 0 & $0 \cdot 223$ \\
\hline \multicolumn{6}{|l|}{ Mid } \\
\hline \multirow[t]{3}{*}{$s m / s M$} & 22 & $L$ & 244 & $0 \cdot 250$ & 0.359 \\
\hline & & $M$ & 294 & 0.750 & 0.414 \\
\hline & & $S$ & 131 & 0 & $0 \cdot 227$ \\
\hline \multirow[t]{3}{*}{$s M / s M$} & 2 & $L$ & 0 & 0 & 0 \\
\hline & & $M$ & 34 & 1 & 0.773 \\
\hline & & $S$ & 18 & 0 & 0.227 \\
\hline \multirow{2}{*}{$\begin{array}{l}\text { Short } \\
\text { (all genotypes) }\end{array}$} & 22 & $L$ & $183\}$ & $0 \cdot 250$ & 0.500 \\
\hline & & $\begin{array}{l}M \\
S\end{array}$ & $\begin{array}{l}122\} \\
360\end{array}$ & 0.750 & $0 \cdot 500$ \\
\hline \multicolumn{6}{|l|}{ Pop. B-9 } \\
\hline \multirow[t]{2}{*}{ Long } & 6 & $L$ & 86 & 1 & 0.400 \\
\hline & & $M$ & 56 & 0 & $0 \cdot 600$ \\
\hline \multicolumn{6}{|l|}{ Mid } \\
\hline \multirow[t]{2}{*}{$s m / s M$} & 16 & $L$ & 100 & 0.250 & $0 \cdot 500$ \\
\hline & & $M$ & 338 & 0.750 & $0 \cdot 500$ \\
\hline \multirow[t]{2}{*}{$s M / s M$} & 4 & $L$ & 0 & 0 & 0 \\
\hline & & $M$ & 116 & $1 \cdot 00$ & $1 \cdot 00$ \\
\hline
\end{tabular}

sidering only the frequency of short versus nonshort progeny was used. This procedure makes no use of the information in the observed frequencies of long- versus mid-styled progeny and so is not fully efficient. However, it does avoid the necessity of classifying the short-styled maternal plants into their four possible genotypes, and concomitant assumptions.

Values of $t$ in the two populations are strikingly different. The three style morphs in B-5 are predominantly outcrossing, with high rates of disas- sortative mating occurring in each of the three style morphs. In contrast in B-9 the $L$ morph is moderately outcrossed, whereas in the $M$ morph no detectable disassortative mating occurred (table 3 ). To examine whether the $t$ values differ among style morphs within populations, chi-square heterogeneity tests were performed (Bailey, 1961). In the trimorphic population there was no significant difference among the estimates $\left(\chi^{2}=1 \cdot 07\right.$, df 2 ). Since the values were homogeneous, a joint estimate of disassortative mating was obtained

Table 3 Estimates of disassortative mating $(t)$ of the floral morphs in two populations of Eichhornia paniculata from Northeastern Brazil. Heterogeneity chi-square values are given for phenotypic proportions in segregating families of floral morphs

\begin{tabular}{|c|c|c|c|c|c|}
\hline & \multicolumn{3}{|c|}{ Populations B-5 } & \multicolumn{2}{|c|}{ Population B-9 } \\
\hline & $L$ & $M$ & $S$ & $L$ & $M^{a}$ \\
\hline Number of families & 21 & 24 & 22 & 6 & 20 \\
\hline Disassortative mating $(t)$ & 0.904 & 0.931 & 0.835 & 0.657 & $0 \cdot 0$ \\
\hline Standard error & 0.034 & 0.052 & 0.077 & 0.068 & 0.083 \\
\hline \multicolumn{6}{|c|}{ Heterogeneity between families } \\
\hline
\end{tabular}

"Majority of $M$ plants with modified short-level stamens.

$* p<0.05, * * * p<0.001$. 
$(t=0.903$, S.E. 0.028$)$. This was significantly different from $1.00(Z=3.47, p<0.001)$, indicating a low level of selfing and/or assortative mating in the population.

In population B-9, estimates of disassortative mating of the style morphs were significantly different $\left(\chi^{2}=37 \cdot 5\right.$, df 1$)$. In addition, estimates for both morphs were significantly different from $1.00(L: Z=5.04, p<0.001, M: Z=12.05, p<$ $0.001)$. Finally, it should be noted that maternal genotypes were assigned by assuming a value of $t=1.0$ to compute the progeny expectations. Since the mid-styled plants in population B-9 were predominantly selfing, this assumed value is inappropriate. However, reference to the "expected" columns in table 2 shows that in this case the assumed value of $t$ will not affect the assignment of $M$ maternal parents to the homozygous and heterozygous category. Only plants giving uniform progenies of $M$ plants will be classified as homozygous. The occurrence of at least one $L$-progeny diagnoses the maternal parent as heterozygous.

\section{DISCUSSION}

The estimation procedures developed in this study were designed to investigate the mating system of style morphs in tristylous populations. At the outset we attempted to estimate the proportion of progeny that were derived from selfed, assortative, and disassortative matings. For the long- and midstyled genotypes, only mid-styled heterozygotes $(\mathrm{sm} / \mathrm{sM})$ provided an estimate of these three mating components. In the remaining genotypes the expectations for assortative and selfed matings are identical. For short-styled genotypes, the expectations for the proportion of short- versus non-shortstyled progeny are also the same under selfing and assortative mating. Consequently, we chose to partition all mating events into two components, namely selfed and disassortative matings. If a significant amount of assortative mating occurs in natural populations our methods will underestimate the true outcrossing rate. In essence the procedure provides an estimate of disassortative mating in tristylous populations.

The model of disassortative mating shares all of the assumptions of the classical mixed mating model (see Clegg, 1980). In addition, it requires that the genotypic structure of the population is known and that each genotype contributes equally to the pollen pool. To obtain information on the relative frequencies of genotypes in populations a large sample of plants was collected in the field and scored for style length, and a smaller sample of families was progeny tested to determine the genotypes of mid- and short-styled maternal parents. Clearly these procedures are subject to sampling error; therefore the standard errors of our estimates are likely to be underestimated. Comparisons of various fitness components of the morphs from population B-5, including flowering time, inflorescence, flower, and pollen grain production, revealed no significant differences among the morphs (Barrett, 1985 $a$ and unpublished data). However, whether genotypes contribute differentially to the effective pollen pool is not known. Despite these difficulties, it would appear that in the case of the trimorphic population (B-5) our model provides an adequate fit to the data (for pooled $t=0.903, \quad \chi^{2}=7.21$, df $5, \quad p>0.05$ ). Unfortunately, because population B-9 is dimorphic, it is not possible to evaluate the goodness-offit of the model to the data since no degrees of freedom are available for the test.

The high frequency of mid-styled plants $(0 \cdot 740)$ in population B-9 is likely to mean that most outcrossing that occurs in this morph is assortative. These matings are not detected by our method and the outcrossing value of $t=0$ that we obtained is therefore likely to be an underestimate of the true value. Evidence to support this suggestion comes from a study of multilocus estimates of outcrossing in Brazilian populations using electrophoretic markers (Glover and Barrett, 1986). Progenies from populations B-5 and B-9 that were used in our study were also screened for enzyme polymorphisms. While the outcrossing estimates for population B-5 were similar, the multilocus estimates for B-9 were $t=0.78$, S.E. $=0.060$ for the long-styled morph and $t=0.36$, S.E. $=0.032$ for the mid-styled morph. The disparity between estimates for the mid-styled morph probably reflects the assortative outcrossed mating component not detected by our method.

The mating systems of the two populations of Eichhornia paniculata from Brazil are strikingly different. At Recife the three floral morphs are highly outcrossed despite strong self-compatibility. In this population, plant density was high and during sampling we observed frequent pollinator visits to flowers. Although these ecological factors are likely to encourage outcrossing, it seems likely that additional influences are involved. Floral trimorphism may promote disassortative pollination among the floral morphs as Darwin (1877) hypothesized, or some form of cryptic self-incompatibility system (Bateman, 1956; Weller and Ornduff, 1977) may favour inter-morph fertilisa- 
tions. We are currently investigating the latter possibility; examination of the former by pollen flow studies (e.g., Barrett and Glover, 1985) is precluded in $E$. paniculata by the absence of a strong pollen trimorphism in the species.

In population B-9 at União dos Palmares, a more complex pattern of mating was revealed. While the long-styled morph has a moderately high rate of disassortative mating $(t=0 \cdot 657)$, no detectable outcrossing was evident in the mid-styled morph. This contrast in mating pattern may largely result from differences in the relative lengths of reproductive organs in the two floral morphs. While the conventional separation of stamens and stigmas is maintained in the long-styled morph, modifications favouring self-fertilisation were apparent in the mid-styled morph. The breakdown of stigma-anther separation (herkogamy) in the mid-styled morph is the result of elongation to filaments of the short stamen set. The modified stamens take up a position next to mid-level stigmas resulting in automatic self-pollination. Curiously, only one of the three short-level stamens within a flower elongates, and not all flowers on a given plant exhibit the modification (Barrett, $1985 a$ ). The genes modifying stamen position in the mid-styled morph are recessive in nature and produce no observable phenotypic effects in the long-styled morph (Barrett, 1985b, and unpublished data). Breakdown of herkogamy in the midstyled morph is also apparent in the related $E$. crassipes (Barrett, 1979). These modifications appear to be the initial stages in the breakdown of tristyly to semi-homostyly in Eichhornia.

Monomorphic populations of E. paniculata are usually fixed for self-pollinating, semi-homostylous mid-styled forms (Barrett, 1985a). This raises the question of whether or not this morph might spread to fixation in population B-9. With the observed mating asymmetry and no major fitness differences between progeny arising from the two morphs, the mid-styled morph should replace the long-styled morph. This process would be further augmented if pollinator service were unreliable, since mid-styled plants are self-pollinating, whereas long-styled plants are not. Measures of inbreeding depression and maternal and paternal fitness components of the morphs are required before the dynamics of selection in dimorphic populations can be more accurately described.

Acknowledgements We thank Mike Clegg, Deborah Glover, Alan Green and Rex Oram for advice and constructive criticism of the manuscript. Research was funded by grants from the Natural Sciences and Engineering Research Council of Canada to S. C. H. Barrett.

\section{REFERENCES}

BAILEY, N. T. J. 1961. Introduction to the Mathematical Theory of Genetic Linkage. Clarendon Press, London.

BARRETT, S. C. H. 1979. The evolutionary breakdown of tristyly in Eichhornia crassipes (Mart.) Solms (Water Hyacinth). Evolution, 33, 499-510.

BARRETT, S. C. H. $1985 a$. Floral trimorphism and monomorphism in continental and island populations of Eichhornia paniculata (Spreng.) Solms. (Pontederiaceae). Biological Journal of the Linnean Society, 25, 41-60.

BARRETT, S. C. H. $1985 b$. Ecological genetics of breakdown in tristyly. In Haeck, J. and Woldendorp, J. W. (eds.) Structure and Functioning of Plant Populations. II Phenotypic and Genotypic Variation in Plant Populations. North-Holland Publishing Co., Amsterdam, pp. 267-275.

BARRETT, S. C. H. AND GLOVER, D. E. 1985. On the Darwinian hypothesis of the adaptive significance of tristyly. Evolution, 39, 766-774

BATEMAN, A. J. 1956. Cryptic self-incompatibility in the wallflower: Cheiranthus cheiri L. Heredity, 10, 257-261.

BRown, A. H. D., MATHESON, A. C. AND EldRidGE, K. G. 1975. Estimation of the mating system of Eucalyptus obliqua L'Herit using allozyme polymorphisms. Aust. J. Bot., 23 , 931-949.

CLEGG, M. T. 1980. Measuring plant mating systems. Bioscience, $30,814-818$

CROSBY, J. L. 1949. Selection of an unfavourable gene-complex. Evolution, 3, 212-230.

DARWIN, C. 1877. The Different Forms of Flowers on Plants of the Same Species. John Murray, London.

GANDERS, F. R. 1975. Mating patterns in self-compatible distyl. ous populations of Amsinckia (Boraginaceae). Can. J. Bot., 52, 773-779.

GLOVER, D. E. AND BARRETT, S. C. H. 1986. Variation in the mating system of Eichhornia paniculata (Spreng.) Solms (Pontederiaceae). Evolution (in press).

LEWIS, D. 1949. Incompatibility in flowering plants. Biol. Rev., 24, 472-496

MATHER, K. 1951. The Measurement of Linkage in Heredity, (2nd edn). Methuen, London.

NF:TTANCOURT, D. 1977. Incompatibility in Angiosperms. Springer-Verlag, Berlin.

SCHOEN, D. J. AND CLEGG, M. T. 1984. Estimation of mating system parameters when outcrossing events are correlated. Proc. Nat. Acad. Sci., 81, 5258-5262.

WELLER, S. G. AND OR NDUFF, R. 1977. Cryptic self-incompatibility in Amsinckia grandiflora. Evolution, 31, 47-51. 